Bauger, E. S. Fundamentos y límites del encarcelamiento preventivo. Algunas consideraciones sobre el nuevo Código Procesal Penal Federal. Derecho y Ciencias Sociales. Noviembre 2019 - Abril 2020 N²2. Pgs 59 - 77 ISNN 1852-2971 Instituto de Cultura Jurídica y Maestría en Sociología Jurídica. FCJ y S. UNLP

\title{
Fundamentos y límites del encarcelamiento preventivo. Algunas consideraciones sobre el nuevo Código Procesal Penal Federal
}

Fundamentals and limits of preventive imprisonment. Some considerations on the new Federal Criminal Procedure Code

Erika Silvina Bauger

\section{Resumen}

Si de investigación criminal se trata, un tema que nos motiva una profunda preocupación es el referido al instituto de la prisión preventiva, es decir, la privación de libertad de una persona sospechada de haber delinquido, durante toda la etapa en que perdure la investigación criminal hasta la etapa que culmine en un juicio de verdad respecto de su responsabilidad en el hecho atribuido. En este trabajo me propongo analizar los fundamentos y límites del instituto a la luz de la reforma del Código Procesal Penal Federal.

Palabras clave: prisión preventiva, Código Procesal Penal Federal

\section{Abstract}

If a criminal investigation is concerned, an issue that motivates us a deep concern is referred to the institute of pretrial detention, ie the deprivation of liberty of a person suspected of having committed a crime, during the entire period in which the criminal investigation until the stage that culminates in a truth trial regarding its responsibility in the act attributed. In this paper I intend to analyze the foundations and limits of the institute in light of the reform of the Federal Criminal Procedure Code.

Key words: preventive prison, Code of Criminal Procedure Federal

\footnotetext{
- Abogada, egresada con Diploma de Honor y Medalla de la UNLP. Premio "Joaquín V. González". Auxiliar Docente con funciones de Adjunta de la Cátedra I de Derecho Internacional Privado de la FCJyS. de la UNLP. Especialización en Derecho Internacional Privado de la Universidad de Salamanca. Miembro del AADI, ASADIP e Instituto de Derecho Internacional Privado del Colegio de Abogados de La Plata. Becaria de investigación en Iniciación, Perfeccionamiento y Formación Superior de SECyT de la UNLP. Maestranda en Relaciones Internacionales y en Derechos Humanos de la UNLP. Estudiante de la Especialización en Docencia Universitaria de la UNLP. Integrante de la Red de Profesoras de la FCJyS y del Observatorio de Enseñanza del Derecho de la UNLP. ebauger@gmail.com, ebauger@jursoc.unlp.edu.ar. https://orcid.org/0000-0002-6207 -4203
} 


\section{Fundamentos y límites del encarcelamiento preventivo. Algunas consideraciones sobre el nuevo Código Procesal Penal Federal}

Erica S. Bauger

\section{I.-Introducción}

La clásica noción del instituto como disposición cautelar del reo, ya había recibido desde antaño, un gran número de críticas puesto que se la consideraba una pena de prisión adelantada por un delito que aún no estaba plenamente acreditado. En este sentido resulta oportuno recordar aquellas amargas reflexiones de Carnelutti (1965) cuando expresaba: "Así se aclara el inevitable altísimo costo del instituto penal: nosotros nos encontramos en definitiva encerrados en este círculo vicioso de que para saber si se debe castigar, se debe comenzar por castigar. Esta es, quizá la verdad por la cual ha sido más gravemente conmovida mi fe en el Derecho". Hace ya más de dos siglos Beccaria (1955: 179) sostenía, en un contexto histórico en el que el encarcelamiento de toda persona acusada de un delito era la regla, que "el rigor de la cárcel sólo debe ser el necesario para impedir la fuga o para que no se oculten las pruebas de los delitos".

De ese modo, sentaba las bases de lo que luego, una vez operadas las revoluciones liberales del siglo XVIII y de que el estado de inocencia fuera elevado a la categoría de principio fundamental ${ }^{1}$, sería la única justificación con algún viso de razonabilidad de la restricción de libertad de quien todavía no ha sido condenado: el encarcelamiento preventivo. El cual procede, de acuerdo a una visión liberal del problema, solamente como medida cautelar para asegurar los fines del proceso, esto es, la averiguación de la verdad y la efectiva aplicación de la ley penal.

Luego de recordar el sinuoso camino recorrido por la privación de la libertad durante el proceso desde que esos motivos fueron insinuados como justificación, en la actualidad, Ferrajoli (1997) sostiene como tesis, que fueron precisamente dichas excepciones a la libertad, las que operaron como vía de entrada a justificaciones basadas ya no en motivos estrictamente procesales sino de prevención y defensa social, que el mismo autor destaca que, por definición, sólo son aplicables cuando la pena ya ha sido impuesta.

Para Ferrajoli "la debilidad de esta posición de compromiso, que ha demostrado ser incapaz de contener el desarrollo patológico de la privación de libertad sin juicio, radica en su incoherencia con la proclamada presunción de inocencia, enmascarada bajo el patético sofisma de la naturaleza no penal del instituto". Señala, a su vez que: "Los principios ético-políticos, como los de la lógica, no admiten contradicciones, so pena de inconsistencia...y una vez admitido que un ciudadano presunto inocente puede ser encarcelado por 'necesidades procesales', ningún juego de palabras puede impedir que lo sea también por 'necesidades penales"'. Sobre esta base, asevera que Manzini tenía razón cuando, aguijoneando a los doctrinarios liberales, este autor se preguntaba por qué no se aplicaba el principio con todas sus lógicas consecuencias y se abolía directamente la prisión provisional, para concluir que "si no

\footnotetext{
${ }^{1}$ Cf. Art. 9 de la Declaración de Derechos del Hombre y del Ciudadano de 1789 según el cual: "debiéndose presumir inocente a todo hombre mientras no se lo haya declarado culpable, si su arresto hubiera sido considerado indispensable, todo rigor que no sea necesario para asegurar su persona debe ser severamente reprimido por la ley".
} 
se quiere reducir la presunción de inocencia a puro oropel inútil, debe aceptarse esta provocación de Manzini, demostrando que no sólo el abuso, sino ya antes el uso de este instituto es radicalmente ilegítimo y además idóneo para provocar, como enseña la experiencia, el desvanecimiento de todas las demás garantías penales y procesales” (Ferrajoli, 1997: 555).

En un momento en el que la política criminal diseñada por los medios de comunicación exacerba permanentemente la sensación de inseguridad de la población; en el que la sociedad reclama una reacción estatal inmediata ante cualquier presunta infracción a las normas penales; en el que, por esta misma razón, se escucha a diario que se debe aplicar la prisión antes del juicio para evitar que los "delincuentes" sigan cometiendo delitos; en el que se critica al sistema penal porque "los delincuentes entran por una puerta y salen por la otra" sin importar que el proceso continúe y eventualmente culmine, en caso de demostrarse la culpabilidad del imputado, con la aplicación legítima de una pena; en un momento en el que, en suma, se olvida que las garantías obran como límites al poder del Estado en favor de todos los ciudadanos, inclusive en favor de aquéllos que reclaman que la prisión preventiva actúe como mecanismo de prevención sin advertir que cualquiera puede resultar imputado de un delito, esta invitación a prescindir directamente de la prisión preventiva no debe ser tomada como un mero ejercicio lúdico consistente en "doblar la apuesta", sino como base para una seria reflexión posiblemente ésta, sea la intención del autor citado- acerca de si existen fundamentos, y en su caso, cuáles son los límites, para que el Estado prive de libertad a sus ciudadanos en forma previa a una sentencia que declare su culpabilidad.

\section{II.- El esquema constitucional}

\section{II.1.- Equiparación del arresto con la prisión preventiva}

Es sabido que el derecho a la libertad ambulatoria reconocido a todos los habitantes de la Nación por el art. 14 de la Constitución Nacional, sólo puede ser restringido por el Estado a título de pena luego de un proceso regular y legal en el que se declare la culpabilidad de una persona por haber cometido un hecho punible.

De esta garantía de juicio previo, que se encuentra expresamente prevista en el art. 18 de nuestra Carta Magna, se deriva otra garantía implícita, conocida en doctrina como principio de inocencia, que tiene directa incidencia a la hora de analizar si el Estado se encuentra autorizado -y en su caso, con qué alcance- a aplicar actos de coerción sobre el imputado durante el proceso penal.

Dado que la libertad ambulatoria es la regla, que la pena sólo puede ser aplicada luego del juicio y que la Constitución Nacional consagra un estado jurídico de inocencia del imputado que permanece incólume hasta que sea objeto de una sentencia judicial que lo declare culpable, cabe preguntarse, entonces, si la consecuencia necesaria es que al Estado le está directamente prohibido restringir la libertad durante el proceso.

A esta pregunta se ha contestado por lo general en forma negativa, haciendo hincapié en la regla establecida también en el art. 18 de la Constitución Nacional según la cual nadie puede ser "arrestado sino en virtud de orden escrita de autoridad competente" (Vélez Mariconde, 
1982: 482-487) (Clariá Olmedo, 1966: 209-213) (Maier, 1996: 511-512 y 520-521); (Cafferata Nores, 1988: 4-7).

La elección de la voz "arrestado" para fundar la restricción de la libertad, en un ámbito en el que es reconocido que las medidas de coerción que pueden recaer sobre el imputado no se resumen en el encarcelamiento preventivo, obliga a precisar la pregunta antes formulada. Está bien, los órganos del Estado pueden arrestar antes de una sentencia firme; pero ¿también pueden encarcelar preventivamente?

En este sentido, no se puede dejar de advertir que la utilización de ese vocablo parecería indicar, a primera vista, que lo que se pretendió con la inclusión de esta fórmula fue fundar el derecho de habeas corpus a fin de proteger al individuo contra las detenciones arbitrarias (González, 1983: 184-189).

La diferencia de entidad entre el arresto autorizado expresamente por el texto constitucional y el encarcelamiento preventivo ha sido puesta de relieve por Daniel Pastor (1993: 47) al destacar que: "pareciera ser que esa regla se refiere a casos de detenciones breves, pero nunca a la prisión preventiva o provisional tal cual hoy la conocemos, es decir, con un grado de estabilidad que la prolonga indefinidamente en el tiempo"

La doctrina mayoritaria utiliza diversos caminos para negar tal distinción o, al menos, para obviar que allí podría existir un problema para fundar el status constitucional de la prisión preventiva. Nelson Pessoa, v.gr., luego de transcribir la fórmula, y sin otra argumentación, concluye que "la citada regla es el sustento constitucional de la privación de la libertad con anterioridad al fallo definitivo. Para ser más exacto, es el fundamento del auto de procesamiento y de la consiguiente prisión preventiva" (Pessoa, 1992: 148).

Vélez Mariconde (1982: 484) analiza la cuestión a partir del estudio conjunto de los arts. 18 y 61 (actual 69) de la Constitución Nacional, señalando que si el art. 61 autoriza la aprehensión sin orden de los legisladores cuando son sorprendidos in fraganti delito, mal puede sostenerse que nuestra Carta Magna requiera de orden de autoridad competente para disponer la aprehensión de personas que no tienen ese privilegio. La orden tiene que resultar, entonces, necesaria para algo más que la mera aprehensión: "el tecnicismo de la Constitución Nacional no se ajusta al que siguen (en general) las leyes procesales argentinas...cuando la primera se refiere a un 'arrestado', no alude al arresto o a la aprehensión que reglamentan las segundas, sino a un estado privativo de la libertad, el que sólo puede ser impuesto por mandato escrito de autoridad competente".

Clariá Olmedo apela, por su parte, a argumentos de tipo histórico. Así, recuerda que "ya la Revolución francesa, en cuyos principios se inspiró en definitiva nuestro sistema democrático de gobierno, contempló la necesidad de estas medidas de coerción. En efecto, la declaración de los Derechos del Hombre y del Ciudadano, inmediatamente de proclamar el principio de inocencia, en el mismo art. IX prevé la indispensabilidad del 'arresto' mediante la declaración según la cual debe ser severamente reprimido por ley todo rigor que no sea necesario para esa finalidad de aseguramiento. La voz 'arresto' debe ser entendida como cualquier tipo de privación de la libertad de quien sea pasible de una imputación. Ese mismo sentido, han de tener en general todas nuestras normas constitucionales, aún cuando en algunos casos sea dificultoso obtener su verdadero alcance. La Constitución nacional es expresa en cuanto a 
autorizar la afectación de la libertad individual cuando sea necesario para evitar un daño jurídico, y al mismo tiempo establece las garantías y limitaciones para su legitimidad. En efecto, en la determinación de las garantías procesales enunciadas por el art. 18, se autoriza expresamente el arresto siempre que se cumpla en virtud de orden escrita de autoridad competente" (Clariá Olmedo, 1966: 213).

Aunque parece coincidir con los autores citados en cuanto a que dicha fórmula es la que da base constitucional a la prisión preventiva, es más difícil aseverar sin lugar a dudas que Maier llega a la misma conclusión. En efecto, este autor también parte de la declaración francesa de 1789 para marcar que nuestra Constitución "sigue esos pasos: pese a impedir la aplicación de una medida de coerción del Derecho material (la pena) hasta la sentencia firme de condena, tolera el arresto por orden escrita de autoridad competente, durante el procedimiento de persecución penal $(\mathrm{CN}, 18) "$, pero en ningún momento equipara expresamente arresto con prisión preventiva sino que, inclusive, aclara que esa oración "funda, en principio, el derecho de habeas corpus, derecho que consiste en la posibilidad de pretender que un juez haga cesar la privación de libertad o la amenaza actual de privación de libertad que arbitrariamente sufre una persona, pues no se funda en la orden escrita de una autoridad competente" (Maier, 1996: 511). El esfuerzo por equiparar arresto con prisión preventiva es ya un indicio de lo difícil que resulta fundar el instituto de la encarcelación provisional en alguna cláusula expresa de la Constitución.

Más allá de ello, y sin perjuicio de que resulta opinable que sea necesario que la Constitución mediante una fórmula expresa haga mención a la prisión preventiva para sostener, sobre esta base, la legitimidad de una privación de la libertad estable previa a la condena, no parece que las razones enunciadas por la doctrina mayoritaria sean concluyentes para justificar la equiparación que se propone.

No lo son las que se basan en los antecedentes históricos, porque no se explica con qué fundamento, más que la sola voluntad del intérprete, se amplía el contenido de la voz arresto prevista en el art. 9 de la Declaración de los Derechos del Hombre y del Ciudadano a una institución que presenta caracteres de estabilidad de los que carece el primero. Desde esta óptica, tampoco se explica cómo se hace para transformar el derecho de habeas corpus -que se reconoce contenido en la oración- en el fundamento de la prisión preventiva. Por último, tampoco parece determinante la remisión al art. 61 (actual 69) de la CN, en tanto no se dirime por qué la contracara de una aprehensión in fraganti deba ser necesariamente la prisión preventiva y no una mera detención arbitraria, especialmente cuando la permanente referencia al derecho de habeas corpus, parece referir la cláusula exclusivamente a esta última situación.

\section{II.2.- Las garantías "al revés"}

En el punto II.1. efectué un repaso de los diversos argumentos brindados por la doctrina mayoritaria para fundar la naturaleza constitucional de la prisión preventiva en una cláusula que prohibe el arresto si no se dan ciertas condiciones.

No se puede aseverar con fundamento que esta doctrina pudiera prever las consecuencias extremas a las que una interpretación de este tipo podía llegar. Sin embargo, esa posibilidad se 
encontraba latente en la base misma de dichas argumentaciones; puesto que desde el análisis de una garantía, que por definición se ha establecido a favor del imputado, se ha argumentado que en realidad la misma corresponde a una potestad del Estado. Ello nos lleva a avizorar que en el futuro no existe óbice para dar un paso más y transformar definitivamente dicha garantía en un "derecho de la sociedad".

Por esta vía se llega, entonces, a la desnaturalización de todo el sistema de garantías constitucionales. Aunque a esta altura de la civilización se debería recordar que éstas constituyen un límite al poder del Estado y no su fuente de derechos.

Esta interpretación al revés de las garantías, ha sido calificada como "perversa porque conduce al destino de que los individuos prefieran no estar amparados por las garantías constitucionales" (Pastor, 1997: 681-683) y sólo por eso "debería merecer la repulsa de nuestros tribunales y no su bendición" (Carrió, 1994: 42).

La inversión del sistema que conlleva esta interpretación, obliga asimismo, a reflexionar acerca de la posibilidad de que el Ministerio Público impugne por la vía del recurso extraordinario una decisión que tiene como efecto la liberación del imputado. Al respecto, Carrió sostiene que "esta precisión acerca de que nuestra Corte sólo esta habilitada para tratar recursos contra resoluciones denegatorias de derechos federales, no siempre ha sido observada. Nuestros fiscales, sin que se entienda bien con qué fundamentos o por invocación de qué derechos, suelen interponer recursos extraordinarios en temas atinentes a la inviolabilidad del domicilio, o al derecho del individuo a no declarar contra sí mismo, simplemente porque el fallo de la Cámara es contrario a sus intereses. La Corte, paralelamente, suele admitir estos recursos sin que se advierta tampoco cuál es el derecho federal que ampararía al representante del Ministerio Público".

Esta apreciación es correcta. Al menos lo es cuando lo que está en discusión es la inteligencia de una garantía constitucional, porque éstas por su propia naturaleza sólo generan derechos a favor del imputado. Empero, el Ministerio Público sí podría tener habilitada la vía del recurso extraordinario en aquellos supuestos en los que la liberación del imputado se funda en la previa declaración de invalidez de las leyes que regulan la prisión preventiva y la excarcelación (art. 14 , inc. $1^{\mathrm{o}}$ de la ley 48 , y ello siempre que se pueda salvar el escollo relativo a la cuestionada naturaleza federal de las leyes procesales dictadas por el Congreso de la Nación).

\section{II.3.- Los tratados de derechos humanos}

La reforma constitucional de 1994 al conferir jerarquía constitucional a una serie de tratados internacionales de derechos humanos que regulan expresamente el derecho a la libertad personal, el principio de inocencia y la prisión preventiva, ha puesto fin a la discusión lingüística, puesto que ya no hace falta recurrir a la libertad ambulatoria prevista en el art. 14 de nuestra constitución histórica, para enunciar el derecho más específico consistente en no ser privado arbitrariamente de la libertad, al juicio previo para dar fundamento al principio de inocencia, ni al arresto para encontrar una fórmula que permita dar cabida a la prisión preventiva en la Constitución. 
Tanto el sistema universal como el sistema interamericano de protección de los derechos humanos consagran estos principios de manera expresa, constituyendo para el Estado argentino una obligación su cumplimiento bajo pena de responsabilidad por incumplimiento de los tratados.

Por su parte, en el ámbito de la Organización de Estado Americanos, la Convención Americana sobre Derechos Humanos establece de modo positivo que toda persona tiene derecho: a la libertad personal (art. 7.1.); a no ser privado de su libertad física, salvo en las condiciones previstas de antemano en las Constituciones Políticas de los Estados (art. 7.2); si está detenida, a ser juzgada en un plazo razonable o a ser puesta en libertad, sin perjuicio de que continúe el proceso (art. 7.5); y si se encuentra inculpada de un delito, a que se presuma su inocencia mientras no se establezca legalmente su culpabilidad.

A su vez, y más allá de que la citada Convención ha sido la que mayor incidencia ha tenido en nuestro ámbito, porque el sistema de reclamos que ésta contempla ha suscitado la efectiva intervención de la Comisión Interamericana de Derechos Humanos en diversos reclamos contra la Argentina, reglas similares se encuentran en el Pacto Internacional de Derechos Civiles y Políticos en el que se dispone: arts. 9.1: el derecho a la libertad personal y a que sólo se prive de ella en las condiciones fijadas por la ley; 9.3: el derecho de toda persona a ser juzgada en un plazo razonable o a ser puesta en libertad; 14.2: el derecho de toda persona acusada de un delito a que se presuma su inocencia mientras no se pruebe su culpabilidad ${ }^{2}$.

Por su parte, tanto en la Convención Americana como en el Pacto se establece que la libertad puede ser restringida con exclusivos fines procesales. En este sentido, la primera dispone que "la libertad (de toda persona) podrá estar condicionada a garantías que aseguren su comparecencia a juicio" (art. 7.5) mientras que el segundo enuncia como principio, que la prisión preventiva no debe ser la regla general, pero autoriza que la libertad pueda quedar subordinada a garantías que aseguren la comparecencia del acusado al juicio y, en su caso, la ejecución del fallo (art. 9.3).

Ahora bien, la mayor claridad de las fórmulas plasmadas en estos tratados y, en particular, la expresa mención a la prisión preventiva ¿ha producido un cambio cualitativo del encarcelamiento preventivo? O, dicho de otra manera ¿es posible sostener que a partir de la reforma este instituto ha adquirido rango constitucional?

Previamente a responder a estos interrogantes, conviene definir con mayor precisión el significado que detenta el hecho de que un instituto posea rango constitucional.

Es sabido que la Constitución establece dos formas de limitaciones a los derechos que reconoce: 1) las generales que ella declara, v.gr. cuando pone como límite de las acciones privadas a los derechos de terceros; y 2) las que confiere al poder de la ley, conforme lo establecido en el art. 14, CN, que supedita el goce de los derechos a las leyes que reglamenten su ejercicio, siempre que por esta vía no se los desconozca o altere en su contenido (art. 28, $\mathrm{CN})$.

\footnotetext{
${ }^{2}$ A su vez, al igual que en la $\mathrm{CADH}$, existe un mecanismo de reclamo ante el Comité de Derechos Humanos, al que, mediante el Protocolo Facultativo, también pueden acceder los particulares. Se encuentran normas similares en la Declaración Americana de Derechos y Deberes del Hombre: art. 1, libertad; art. 26, estado de inocencia; art. 25, derecho a ser juzgado sin dilaciones o a ser puesto en libertad; y en la Declaración de Derechos Humanos: art. 3, libertad; art. 11.1, inocencia.
} 
La referencia expresa a la prisión preventiva presenta, en este contexto, el efecto de clasificar al instituto como limitación de la primera categoría. Sin embargo, el hecho de que se trate de una limitación enunciada por la propia Constitución (en el caso, por el propio tratado) no convierte a la prisión preventiva en un instituto de naturaleza constitucional, al menos si con esta frase se quiere significar que se trata de un mandato de la Constitución. Ello, porque si mañana se borrara la prisión preventiva de todos los códigos procesales ésta no sufriría afectación alguna. En el mismo sentido, si se interpreta que el instituto responde a una manifestación de un derecho de la sociedad reconocido por la Constitución, cabe destacarse, que su inclusión expresa, de modo alguno altera la regla que prohibe derivar facultades para el Estado a partir de las garantías del imputado.

Por tanto, la referencia explícita que hacen los tratados debe ser entendida como una reafirmación del carácter relativo del derecho a la libertad durante el proceso, lo cual no implica que la prisión preventiva haya dejado de ser, solamente, una consecuencia de rango legal no necesaria del sistema.

La reafirmación del carácter no absoluto de los derechos implicados, tendrá a su vez, consecuencias en lo que refiere a la posible tacha de inconstitucionalidad de las normas que regulan el encarcelamiento preventivo. Toda vez que ahora, sin duda, se trata de una limitación impuesta por la misma Constitución, mientras la reglamentación se mantenga dentro de ciertos límites, resultarán más débiles las posturas que sostienen la directa incompatibilidad entre la prisión preventiva y la Constitución. (Pérez Barberá, 1992: 1070-1077).

\section{III.- Límites}

\section{III.1.- El principio de excepcionalidad}

Si conforme a los principios enunciados en los tratados mencionados en el punto anterior, toda persona tiene derecho a la libertad personal y debe ser tratada como inocente hasta que una sentencia firme lo haya declarado culpable, su libertad, necesariamente, sólo puede ser restringida de modo excepcional.

Sin embargo, a pesar de que esta característica es inherente al encarcelamiento preventivo, el análisis de los documentos oficiales de los últimos quince años demuestra que en la Argentina la norma que prohibe que la prisión preventiva sea la regla general (ahora plasmada en forma expresa en el art. 9.3. del Pacto) no pasa de ser una mera expresión de buenos deseos.

Las cifras oficiales nos demuestran acabadamente, que existe un desfasaje entre la proclamada excepcionalidad del encarcelamiento preventivo y la realidad. A pesar de que el principio es sostenido en forma prácticamente unánime por la doctrina y que los responsables de la sanción de las leyes se rasgan las vestiduras mientras declaman que "la prisión preventiva debiera ser la excepción, y la libertad, la regla", lo cierto es que en la práctica, ya sea por efecto de las propias normas o como resultado de su interpretación, ese modelo no aparece cumplido.

Por supuesto que para tener un cuadro completo, habría que contar no sólo con estadísticas de la relación procesados-condenados, sino también con estudios que reflejaran la relación entre procesados en libertad y procesados con prisión preventiva efectiva: Para regular racionalmente la cuestión, también se debería contar con estadísticas que reflejen: 1) qué 
proporción de las personas que permanecen en libertad terminan profugándose; 2) cuál es el porcentaje de prófugos que vuelven a ser detenidos. Empero, las que se encuentran a disposición constituyen un indicio serio de la distorsión del sistema que el abuso de la prisión sin condena está generando en el país.

Como parámetro de análisis podemos considerar las últimas observaciones finales realizadas a Argentina por el Comité contra las Desapariciones Forzadas de Naciones Unidas de fecha 12 de diciembre de 2013, donde se manifiestan grandes preocupaciones por la existencia de normas nacionales que permiten la detención administrativa, sin orden judicial previa o control judicial posterior y fuera de los supuestos de flagrancia. Asimismo, la falta de un protocolo de actuación uniforme para todas las autoridades del Estado a cuyo cargo se encuentran personas privadas de libertad, junto a la ausencia de un sistema de registros informatizado y uniforme que cubra todo el territorio nacional ( $\mathrm{CED} / \mathrm{C} / \mathrm{ARG} / \mathrm{CO} / 1)$.

Las posibilidades de revertir esta situación se asientan en comenzar a aplicar el principio con todas sus consecuencias. En concreto, ello significa que hay que repensar, entre otras cosas, si resulta razonable: que las leyes procesales partan del presupuesto de que se deba dictar la prisión preventiva cuando se dan ciertas condiciones mínimas, v.gr. en el orden nacional, por las cuales no sea procedente una eventual condena de ejecución condicional, a pesar de que en el caso no se advierta algún peligro cierto de frustración del derecho penal material.

Asimismo, resulta esencial analizar si resulta razonable, que en el ámbito legislativo se impongan limitaciones objetivas -a partir de la concordancia entre las normas que obligan a dictar la prisión preventiva y aquéllas que autorizan la excarcelación- que directamente impedirían en muchos casos que los imputados permanezcan en libertad durante el proceso, y que dichas limitaciones objetivas se las interprete como presunciones de fuga que no admiten prueba en contrario.

Repensar y analizar asimismo, la circunstancia de que las leyes procesales utilicen fórmulas ambiguas para justificar la restricción de la libertad en atención a los topes objetivos precedentemente señalados, de modo tal, que mediante la utilización de expresiones como "la objetiva y provisional característica del hecho" o "las condiciones personales del imputado", puedan terminar teniendo cabida interpretaciones peligrosistas que determinen el encierro en el caso concreto por razones de prevención general o especial.

En el ámbito federal, el nuevo Código Procesal Penal Federal ${ }^{3}$, introduce consideraciones en torno al instituto en lo que hace a las medidas de coerción y cautelares.

De conformidad al art. 209, estas medidas se ajustarán a lo que disponen los artículos 15, 16 y 17 del Código, su carácter es excepcional y no podrán ser impuestas de oficio por el juez.

El art. 15 regula las condiciones carcelarias, prohibiendo alojar a personas privadas de libertad en lugares no habilitados, o en sitios que no reúnan las mínimas condiciones de salubridad. Toda medida que conduzca a empeorar injustificadamente las condiciones de detención a presos o detenidos hará responsable a quien la ordene, autorice, aplique o consienta.

\footnotetext{
3 El Decreto 118/2019 aprueba el Código Procesal Penal Federal, aprobado por la Ley $N^{0} 27.063$ con las incorporaciones dispuestas por la Ley $\mathrm{N}^{\mathrm{o}} 27.272$ y las modificaciones introducidas por la Ley $\mathrm{N}^{\mathrm{o}} 27.482$.
} 
Por su parte, el art. 16 establece que las facultades que el Código reconoce para restringir o limitar el goce de derechos reconocidos por la Constitución Nacional o por los instrumentos internacionales de Derechos Humanos deben ejercerse de conformidad con los principios de idoneidad, razonabilidad, proporcionalidad y necesariedad.

El art. 17 consagra que las medidas restrictivas de la libertad sólo podrán fundarse en la existencia de peligro real de fuga u obstaculización de la investigación. Nadie puede ser encarcelado sin que existan elementos de prueba suficientes para imputarle un delito reprimido con pena privativa de libertad, conforme a las reglas de este Código.

Sólo se ejercerá coerción física para obtener la comparecencia de una persona si el mismo fin no pudiere lograrse en tiempo útil, ordenando su citación por las formas que prevé el Código. El art. 210 especifica las medidas de coerción que pueden ser solicitadas por el Ministerio Público Fiscal o el querellante y con el fin de asegurar la comparecencia del imputado o evitar el entorpecimiento de la investigación, la imposición, individual o combinada, de: a. La promesa del imputado de someterse al procedimiento y de no obstaculizar la investigación; b. La obligación de someterse al cuidado o vigilancia de una persona o institución determinada, en las condiciones que se le fijen; c. La obligación de presentarse periódicamente ante el juez o ante la autoridad que él designe; d. La prohibición de salir sin autorización previa del ámbito territorial que se determine; e. La retención de documentos de viaje; f. La prohibición de concurrir a determinadas reuniones, de visitar ciertos lugares, de comunicarse o acercarse a determinadas personas, siempre que no se afecte el derecho de defensa; g. El abandono inmediato del domicilio, si se tratara de hechos de violencia doméstica y la víctima conviviera con el imputado; h. La prestación por sí o por un tercero de una caución real o personal adecuada, que podrá ser voluntariamente suplida por la contratación de un seguro de caución, a satisfacción del juez; i. La vigilancia del imputado mediante algún dispositivo electrónico de rastreo o posicionamiento de su ubicación física; j. El arresto en su propio domicilio o en el de otra persona, sin vigilancia o con la que el juez disponga; $\mathrm{k}$. La prisión preventiva, en caso de que las medidas anteriores no fueren suficientes para asegurar los fines indicados. El control sobre el cumplimiento de las medidas indicadas en los incisos a) a j) del presente artículo estará a cargo de la Oficina de Medidas Alternativas y Sustitutivas, cuya creación, composición y funcionamiento será definida por una ley que se dicte a tal efecto.

\section{III.2.- Mérito sustantivo}

Es una condición necesaria para disponer el encarcelamiento preventivo de una persona que, como resultado de la investigación desarrollada por el Estado, se encuentre acreditado con un alto grado de probabilidad, que ha existido un hecho delictivo y que ese hecho le puede ser imputado de acuerdo con las reglas que regulan la autoría y la participación criminal.

Sobre este límite al poder coercitivo del Estado no existe discusión alguna. En el orden nacional, esta exigencia se verificaba en la obligación de decretar el procesamiento (art. 306 del CPP Nación, en el que se debería efectuar una análisis de las pruebas que justifican la imputación) en forma previa a dictar el auto de prisión preventiva y en la correlativa obligación 
de disponer la libertad de las personas que se encontraran detenidas en el supuesto de que no se hubiera alcanzado ese grado de convicción (art. 309, CPP Nación).

En el nuevo Código Procesal Penal Federal se regulan las condiciones y requisitos de las medidas de coerción, debiendo el Fiscal o el querellante: a. Acreditar que existen elementos de convicción suficientes para sostener la probabilidad de la existencia del hecho y la participación del imputado en éste; b. Justificar suficientemente, con arreglo a las circunstancias del caso y a las personales del imputado, la presunción de que aquél no se someterá al procedimiento u obstaculizará la investigación o la realización de un acto concreto del proceso; c. Indicar el plazo de duración de la medida que estime necesario, según las circunstancias del caso.

El juez controlará la legalidad y razonabilidad del requerimiento y resolverá fundadamente, reglando la normativa el procedimiento para la imposición de una medida de coerción, garantizando los principios de contradicción, inmediación, publicidad y celeridad. No se podrá aplicar una medida de coerción sin expreso pedido del representante del Ministerio Público Fiscal o del querellante. Las partes aportarán los elementos probatorios en una audiencia, a los efectos de constatar las condiciones de procedencia de una medida de coerción, y la Oficina de Medidas Alternativas y Sustitutivas efectuará un informe sobre las condiciones personales y circunstancias que permitan discutir a las partes respecto de la libertad del imputado. En dicha audiencia, el representante del Ministerio Público Fiscal deberá especificar el plazo de duración de la medida y el plazo requerido para llevar adelante la investigación penal preparatoria. En el caso que sea solicitada únicamente por el querellante, deberá exponer la duración y los motivos de su extensión.

El juez dará al imputado el derecho de ser oído, con la asistencia e intervención de su defensor, oportunidad en la que podrá cuestionar el lugar y demás condiciones de la prisión preventiva. Asimismo, escuchará al querellante, cuando éste solicite tomar intervención, y resolverá inmediatamente el planteo.

El requerimiento de una medida cautelar será formulado por las partes ante el juez. Deberá especificar el alcance, plazo de duración y fundamentos de la medida. El juez podrá convocar a audiencia unilateral previo a tomar la decisión. La resolución que imponga una medida de coerción o cautelar deberá individualizar al imputado, enunciar los hechos que se le atribuyan, su calificación legal, expresar las circunstancias que dan fundamento a la medida y fijar el plazo por el cual se establece. Las partes podrán en cualquier momento solicitar la revisión de la medida de coerción ante el juez, por el mismo procedimiento. La resolución que imponga, renueve o rechace la prisión preventiva o cualquier otra medida de coerción o cautelar será revisable, sin efecto suspensivo, dentro del plazo de setenta y dos horas.

El art. 224 establece límites de la prisión preventiva haciéndola cesar cuando: a. Si el imputado hubiere cumplido en prisión preventiva la pena solicitada por el representante del Ministerio Público Fiscal; b. Si el imputado hubiere agotado en prisión preventiva un tiempo igual al de la pena impuesta por la sentencia no firme; c. Si el imputado hubiere permanecido en prisión preventiva un tiempo que, de haber existido condena, le habría permitido solicitar la libertad condicional o la libertad asistida. 
Se establece también como límite la imposibilidad de imponerse nuevamente la prisión preventiva en el mismo proceso si una anterior hubiese cesado por cualquiera de las razones enunciadas precedentemente; ello sin perjuicio de las facultades para hacer comparecer al imputado a los actos necesarios del proceso o de la aplicación de otras medidas de coerción.

El art. 226 establece que el juez, de oficio o a petición del imputado o su defensa, dispondrá la revocación o sustitución de la medida de coerción que hubiere sido impuesta, cuando hayan desaparecido los presupuestos en que se hubiere fundado su imposición.

\section{III.3. Motivos (exclusivamente procesales)}

El alto grado de sospecha es una condición necesaria pero no suficiente para que el Estado pueda privar de libertad a una persona jurídicamente inocente.

Toda vez que los fines propios de la pena sólo podrán verse legítimamente satisfechos luego de que la culpabilidad haya sido declarada por sentencia firme, los únicos motivos que podrían justificar, en alguna medida, la privación de libertad anterior a la condena tienen que ser, necesariamente, distintos de los que justifican la aplicación del derecho penal material.

Como se ha visto, desde Beccaria en adelante, se ha entendido que las razones que autorizan dicha medida de coerción son el peligro de fuga del imputado y el peligro de entorpecimiento de la investigación. El fundamento de la restricción de la libertad con base en esos peligros encuentra a su vez su fundamento en la salvaguarda de los fines propios del proceso, los que han sido sintetizados con las fórmulas "correcta averiguación de la verdad" y "efectiva actuación de la ley penal".

Aunque se deba señalar que ambos fines no son de la misma categoría, porque la efectiva actuación de la ley penal es en realidad el fin último del proceso penal, mientras que la averiguación de la verdad es sólo un medio para alcanzar dicho extremo, en tanto el Estado sólo se encuentra legitimado para aplicar una pena si previamente ha probado que la hipótesis delictiva que está en la base de la imputación encuentra correlato en la realidad, lo cierto es que no parece irrazonable que encarcelamiento preventivo se sustente en los dos riesgos indicados. Cuando el imputado ejerce medidas concretas para obstaculizar la obtención de pruebas, v. gr., intimidando a testigos que podrían declarar en su contra, simultáneamente está afectando, fuera del marco del derecho de defensa, el legítimo proceso de conocimiento que necesariamente debe preceder a una eventual sentencia condenatoria. En estas condiciones, en casos graves y en los que el peligro se encuentre debidamente justificado, resulta factible la privación de libertad durante el lapso estrictamente necesario para permitir la producción de un medio de prueba previamente identificado ${ }^{4}$.

\footnotetext{
${ }^{4}$ Así lo ha entendido la CIDH en el informe 2/97, casos 11.205 y otros, Argentina, 11/3/97, al sostener que la complejidad de la causa puede justificar la restricción de la libertad, en especial en aquellos casos que requieren de interrogatorios difíciles de llevar a cabo, y en los que el acusado ha impedido, demorado o conspirado con otros imputados para perjudicar el normal desarrollo del proceso. También se justifica cuando concurre el riesgo de que los testigos u otros sospechosos puedan ser amenazados. Sin embargo, se aclara: 1) que una vez que la investigación se ha realizado, los interrogatorios de los imputados han concluido y los testigos han declarado, este motivo por sí solo no alcanza para justificar el mantenimiento de la prisión preventiva; 2) que no es legítimo invocar las necesidades de la investigación de manera general y abstracta, sino que, tanto el riesgo de colusión como el de presión sobre los testigos u otros sospechosos, debe ser fehacientemente demostrado por las autoridades judiciales (puntos 33, 34 y 35).

Con mayor precisión esta interpretación ya había sido formulada en el informe 12/96, caso 11.245, Argentina, del 1/3/96, en el que la CIDH había puesto de manifiesto que "el objetivo de la detención preventiva es asegurar que el 
El nuevo texto del Código Procesal Penal Federal, establece en cuanto al peligro de entorpecimiento, conforme al art. 222, se deberá tener en cuenta la existencia de indicios que justifiquen la grave sospecha de que el imputado: a. Destruirá, modificará, ocultará, suprimirá o falsificará elementos de prueba; b. Intentará asegurar el provecho del delito o la continuidad de su ejecución; c. Hostigará o amenazará a la víctima o a testigos; d. Influirá para que testigos o peritos informen falsamente o se comporten de manera desleal o reticente; e. Inducirá o determinará a otros a realizar tales comportamientos, aunque no los realizaren.

La privación de libertad fundada en el peligro de fuga presenta, por su parte, una doble finalidad: en primer lugar, intenta prevenir la paralización del proceso derivada de la imposibilidad -o al menos la inconveniencia- de desarrollar el juicio en rebeldía; y, en segundo término, intenta prevenir que, una vez culminado el mismo, no se frustre el cumplimiento de la pena por la ausencia del imputado.

En la primera de estas finalidades encuentra Maier (1996) la "razón principal por la que se autoriza la privación de libertad del imputado durante el procedimiento porque, no concibiéndose el proceso penal contumacial (en ausencia del imputado o en rebeldía), por razones que derivan del principio de inviolabilidad de su defensa, su presencia es necesaria para poder conducir el procedimiento hasta el final...".

La posibilidad de fundamentar la privación de la libertad en el derecho de defensa del imputado ha sido, sin embargo, cuestionada con serios argumentos por Rusconi, quien entiende que no "parece razonable que de la preocupación por una garantía republicana del imputado aparezca como consecuencia directa la mayor y más terrible violación de los derechos humanos del ciudadano en el proceso y esto quiera ser presentado como lógico", agregando sobre esta base que: "es verdaderamente irrazonable que el proceso penal 'haya preparado las cosas' como para que se tenga que optar entre la vigencia del principio de inocencia y su consecuencia de libertad del imputado durante el proceso y el mantenimiento de la garantía del derecho de defensa en juicio...en última instancia, la participación del imputado durante el debate es un derecho que le permite 'controlar' la producción de la prueba, contrarrestar el desarrollo del debate y participar en la inclinación del juicio hacia una de las hipótesis. Sin embargo no hay ninguna razón como para imponer esta garantía y no posibilitar que el imputado disponga de ella pareciera que podríamos dar, con muchas ventajas político-criminales, al imputado la opción de presentarse o no al juicio y con ello plantear alternativas lógicas: si se presenta puede participar en el juicio, si no él será responsable de no incorporar al debate buena cantidad de información...¿porqué no aceptar como posible el juicio contra ausentes?" (Rusconi, 1997: 3).

Esta observación pone al descubierto que el motivo principal de la prohibición del juicio en rebeldía no reside en el derecho de defensa del imputado, puesto que éste, por otra parte, bien podría ejercerlo mediante la intervención del defensor técnico.

La explicación para la paralización del procedimiento ante la rebeldía del imputado encuentra su real hontanar en una decisión de política criminal, nunca declarada pero evidente, que se asienta en la idea de no movilizar todo el aparato de persecución del Estado cuando el 
desconocimiento del paradero del imputado permita augurar que la eventual sentencia de condena no podrá ser efectivamente aplicada.

De este modo, la cuestión vuelve a remitirse a la segunda finalidad de la privación de la libertad con base en el peligro de fuga, que el argumento de la contradicción entre el derecho de defensa y el principio de inocencia no parece en condiciones de contradecir.

Consecuentemente, y salvo que se sostenga que el derecho a la libertad y el principio de inocencia son absolutos, se debe concluir que si en el caso concreto es posible acreditar que concurren las condiciones que permiten presumir fundadamente que el imputado se evadirá, generando de ese modo que la eventual condena resulte de cumplimiento imposible, éste será un motivo suficiente para justificar la privación de libertad.

En cuanto al peligro de fuga, el art. 221 del Código Procesal Penal Federal regla determinadas pautas para su evaluación: a. Arraigo, determinado por el domicilio, residencia habitual, asiento de la familia y de sus negocios o trabajo, y las facilidades para abandonar el país o permanecer oculto; b. Las circunstancias y naturaleza del hecho, la pena que se espera como resultado del procedimiento, la imposibilidad de condenación condicional, la constatación de detenciones previas, y la posibilidad de declaración de reincidencia por delitos dolosos; c. El comportamiento del imputado durante el procedimiento en cuestión, otro anterior o que se encuentre en trámite; en particular, si incurrió en rebeldía o si ocultó o proporcionó falsa información sobre su identidad o domicilio, en la medida en que cualquiera de estas circunstancias permitan presumir que no se someterá a la persecución penal.

\section{III.4.- El principio de proporcionalidad procesal}

La posibilidad de que el Estado mantenga en prisión a una persona también se encuentra condicionada por esta regla que prohibe que el encarcelamiento preventivo resulte más grave que la pena que eventualmente pueda ser aplicada.

Ello significa que la prisión preventiva directamente no podrá ser ordenada o, en su caso, deberá cesar, cuando el delito que se imputa no esté reprimido con pena privativa de libertad o el imputado haya sufrido en detención un lapso superior al que pudiere corresponderle en el supuesto de resultar condenado.

Aunque parezca evidente que una persona no debería permanecer encerrada durante el proceso cuando la pena que corresponde al tipo que se imputa no es privativa de la libertad, la recepción legislativa de este concepto sólo tuvo lugar en nuestro país luego de que la Corte del siglo pasado lo fijara como regla al analizar la procedencia de la libertad bajo fianza en relación al delito de rebelión, el que se encontraba sancionado únicamente con la pena de destierro y multa.

En tal sentido, la Corte sostuvo que "los reos de delitos que no son castigados con pena corporal, tienen derecho a que se les ponga en libertad bajo fianza porque de otro modo se aumentaría su sufrimiento más allá de lo necesario para la seguridad de que se cumpla la pena establecida por la ley" ${ }^{\prime 2}$.

parcial del informe en Cuadernos de Doctrina y Jurisprudencia Penal, Ad Hoc, Buenos Aires, año 3, Nros. 4-5, pp. 1077/1093.

${ }^{5}$ Fallos 7:368 (1863). 
Como se ve la Corte solamente estaba haciendo referencia a la posibilidad de limitar el efecto concreto de la prisión preventiva por medio de la excarcelación. Sin embargo, a partir de la regla general allí asentada, los códigos procesales sancionados durante el siglo pasado comenzaron a establecer como límite directo a la prisión preventiva que "al delito o concurso de delitos que se le atribuya (al imputado) corresponda pena privativa de libertad"6, prohibiendo, por tanto, su dictado cuando este requisito no se encuentre cumplido.

El restante efecto del principio de proporcionalidad se pone de manifiesto en aquellas reglas que determinan la excarcelación cuando el imputado ha cumplido en prisión preventiva el máximo de la pena prevista para el delito, o la impuesta por sentencia no firme, o aquélla que le hubiera permitido obtener la libertad condicional en caso de que hubiera recaído condena.

Dentro de estos contornos, y aunque ya de por sí sea un despropósito que resulte necesario establecer legalmente que la prisión preventiva no debe durar más que la pena prevista para el delito, el principio constituye una herramienta de suma importancia a los efectos de limitar la actividad coercitiva del Estado ${ }^{7}$. Se trata de una prohibición absoluta, que se encuentra reafirmada por la sanción prevista en el art. 270 del Código Penal, en virtud de la cual no se puede ordenar o prolongar el encarcelamiento preventivo cuando concurren las condiciones indicadas. $^{8}$

Fuera de estos supuestos (de prohibiciones absolutas) el rendimiento del principio, al menos con el alcance que tradicionalmente se le ha concedido, comienza a tornarse más difuso. En efecto, del mismo modo en que la relación de proporcionalidad entre el encarcelamiento y la pena en expectativa ha justificado la inadmisibilidad de la privación de libertad en los casos anteriores, esa misma relación es la que ha servido de base para que el encarcelamiento preventivo pudiera ser regulado como obligatorio cuando el máximo de la escala penal prevista en forma abstracta en la ley supere cierto límite y no proceda condena de ejecución condicional, sin que resulte necesario analizar si en el caso concreto concurre o no el peligro de fuga que teóricamente se estaría intentando prevenir.

Quien ha advertido acerca de esta consecuencia nociva de un principio que debería operar como límite y no como fundamento del encarcelamiento preventivo ha sido Daniel Pastor al señalar que "el Estado, para aplicar un encarcelamiento preventivo constitucionalmente autorizado, debe probar sus presupuestos. El criterio opuesto al expresado se halla enquistado en nuestra literatura tradicional bajo el manto seudo-garantista del llamado principio de proporcionalidad que, justo es reconocerlo, brindó importantes progresos en los tiempos en que la prisión provisional se aplicaba incluso cuando no se esperaba ninguna pena privativa de la libertad (hechos punibles reprimidos únicamente con multa), pero hoy debe ser abandonado porque sigue justificando encarcelamientos preventivos obligatorios, graves y extensos en casos en los que, por definición legal (constitucional), no se espera pena de ningún tipo: principio de inocencia" (Pastor, 1993: 50); a su vez, en la misma línea de argumentación,

\footnotetext{
${ }^{6}$ El Art. 312 del CPP Nación, que reconocía su fuente directa en el CPP La Pampa de 1964.

${ }^{7}$ La consecuencia moderna más importante del principio de proporcionalidad ha sido la imposición de un límite temporal al encarcelamiento preventivo vinculado a la duración del procedimiento penal.

${ }^{8}$ El art. 270 del Código Penal establece: "Será reprimido con multa de dos mil quinientos pesos como mínimo y en treinta mil pesos como máximo e inhabilitación absoluta de uno a seis años, el juez que decretare prisión preventiva por delito en virtud del cual no proceda o que prolongare la prisión preventiva que, computada en la forma establecida en el Artículo 24, hubiere agotado la pena máxima que podría corresponder al procesado por el delito imputado. (Texto originario con la modificación dispuesta por ley 24.286 en cuanto al monto de la multa).
} 
agrega que: "si, por la escala penal prevista para el delito imputado, en el hipotético caso de llegarse a una condena esta deberá ser de cumplimiento efectivo, entonces siempre, en la escena del proceso, el cumplimiento será adelantado desde la sentencia definitiva hasta el auto de procesamiento, en franca violación al principio de inocencia, dado que, además, ese encarcelamiento preventivo previsto por el CPP no debe cumplir necesariamente función alguna en la neutralización de los peligros procesales que, según la teoría, autorizan la imposición de la prisión preventiva: basta el monto de la pena que se espera; los peligros procesales...se presumen".

Sin perjuicio de que la referencia al cumplimiento efectivo de la hipotética condena resulta imprecisa porque no siempre que se de esta condición el encarcelamiento preventivo va a ser obligatorio en atención a la forma en que se encuentra regulada la excarcelación, la observación que formula Pastor debe ser especialmente tenida en cuenta en tanto pone al descubierto, una vez más, los peligros que se corren a partir de la inversión de los principios limitativos del poder coercitivo del Estado.

Ello no significa que el principio deba ser desechado sin más. Además de las prohibiciones absolutas a las que ya se ha hecho referencia, el principio puede resultar fructífero si, se lo empieza a pensar con un contenido distinto: no ya como una mera relación entre la cantidad de pena en expectativa y la medida de coerción, sino como una relación entre la medida de coerción y la finalidad que se pretende obtener con ella.

Desde este nuevo enfoque, se sostiene que el principio determina una especie de triple control de la legitimidad de toda medida de coerción, las que sólo estarán justificadas cuando simultáneamente se verifique que resultan necesarias, idóneas y proporcionales a los intereses que se encuentran en conflicto.

Ya sea que se trate de un componente del principio de proporcionalidad, como o un principio autónomo, resulta conveniente detenerse en lo que se ha dado en llamar "principio de necesidad".

Solimine (2003: 640) explica el contenido del principio refiriendo que "sólo cuando aparezca necesario neutralizar el riesgo procesal existente resulta admisible imponer una medida de coerción. De modo que, cuando no exista una situación que ponga en peligro la consecución de los fines del proceso, no corresponde adoptar ninguna medida cautelar de tipo personal".

Sin perjuicio de las diversas consecuencias que podrían derivarse de una regla de esta naturaleza (en particular, respecto de las medidas alternativas al encarcelamiento preventivo), corresponde resaltar que en el anterior Código Procesal Penal de la Nación, las ya mencionadas presunciones legales de fuga que surgían de la combinación entre los topes fijos establecidos en los arts. 312 y 316 y 317 , inc. $1^{\circ}$ del CPP Nación, en virtud de las cuales ciertos delitos resultarían inexcarcelables. En idéntico tenor, las normas del Código de rito de la Provincia de Buenos Aires, siguen un sistema en materia de restricción de la libertad durante el desarrollo del proceso penal que no se adecúa al mandato de las Constituciones de la Nación y de la Provincia de Buenos Aires. Por el contrario, con un método deficiente y casuístico desconocen la esencia del instituto. No obstante, en todos los casos, la normativa habrá de interpretarse con especial atención a lo normado por los artículos 21 y 57 de la Constitución provincial. 
Ello así, pues todos los días los operadores del sistema de enjuiciamiento criminal deciden acerca de la libertad de las personas con un criterio puramente matemático, sin cuestionarse la razonabilidad de las normas que imponen el encarcelamiento obligatorio durante todo el trámite del proceso y, sobre todo, sin preguntarse si es realmente necesario que en el caso concreto un imputado permanezca privado de su libertad a fin de asegurar la actuación de la ley penal.

Consecuentemente, si a pesar de la expectativa de pena, en el caso concreto concurren buenos motivos para entender que el encarcelamiento no resulta necesario para asegurar la correcta actuación de la ley penal, la privación de libertad resultará injustificada.

\section{IV.- Conclusiones}

De todo lo expuesto podemos concluir que resulta inadmisible que se asigne al instituto del encarcelamiento preventivo finalidades propias del derecho penal.

Con mayor o menor éxito, la literatura penal ha intentado justificar la pena estatal en finalidades de prevención general, de prevención especial o, aunque no se trate estrictamente de una finalidad, de retribución por el hecho cometido. Pero éstas sólo pueden comenzar a operar con legitimidad una vez que la persona ha sido condenada. Antes de ese momento, toda privación de libertad que pretenda fundarse en alguno de esos motivos, implicará no ya la relativización del derecho a la libertad personal y del principio de inocencia, sino su directa e inconstitucional anulación.

La vía de entrada tradicional de estas finalidades ajenas al instituto, ha sido la justificación del encarcelamiento preventivo en el peligro de comisión de nuevos delitos y en la alarma social generada por el hecho -presuntamente- cometido. Lamentablemente, la defensa del primero de estos motivos como fundamento del encarcelamiento preventivo, no constituye un patrimonio exclusivo de la doctrina fascista; por el contrario, ha encontrado eco en parte de la doctrina liberal, la que ha entendido que esta medida de coerción se justifica, como una necesidad política, no sólo para prevenir la fuga o el entorpecimiento de la investigación sino también por razones de "defensa pública, para impedirles a ciertos facinerosos que durante el proceso continúen en sus ataques al derecho ajeno" (Carrara, 1859: 375) .

Ya la sola enunciación de la regla, utilizada muchas veces en forma encubierta por nuestro tribunales para justificar el encarcelamiento de imputados con varios procesos en trámite, que deberían permanecer en libertad si se aplicaran las pautas objetivas establecidas por el legislador, permite verificar el escaso valor que los sostenedores de una posición de este calibre están atribuyendo a los principios que deben gobernar la interpretación en este terreno. Ello así, porque sólo se puede justificar el encierro anticipado de un ciudadano, para impedir que "persista en sus ataques al derecho ajeno", si al mismo tiempo se presupone que en realidad es culpable de los delitos que se le están imputando.

Por este camino, la prisión preventiva ve desdibujada su justificación como medida cautelar para convertirse en una auténtica medida de prevención del delito: se libera a la sociedad de los peligros que, con sustento en una ilegítima presunción de culpabilidad, se supone que habrá de generar el sujeto imputado en el futuro. 
Pero, a su vez, en atención al motivo en que se asienta, esta medida de prevención es la más perversa que se podría imaginar; en efecto, aunque pueda resultar discutible, la prevención especial con fundamento en la pena previamente impuesta se justifica en la comprobación judicial de un hecho delictivo ya cometido; en cambio, cuando se pretende argumentar a favor de la privación de libertad sobre la base de hipotéticos nuevos delitos, lo que se está implícitamente sosteniendo es que no sólo no hace falta que culmine el procedimiento relativo al hecho que se está juzgando, sino que tampoco se requiere que el imputado haya siquiera pensado en la comisión de un "nuevo" hecho.

Consecuentemente, la efectiva privación de libertad con base en esta razón constituiría la más grave afectación que podría sufrir el sistema de garantías constitucionales pues no sólo se estaría afectando garantías procesales sino también garantías de naturaleza material. Para decirlo más claramente, el encarcelamiento preventivo justificado en el peligro de comisión de nuevos delitos viola simultáneamente el principio de inocencia y el principio de derecho penal de acto establecido en el art. 19 de nuestra Constitución Nacional, en virtud de aplicarse una pena anticipada por hechos que ni siquiera han tenido comienzo de ejecución.

Por su parte, con la apelación a la fórmula de la "alarma social" se está queriendo significar -ni más ni menos- que, si por algún motivo, el hecho tiene gran repercusión social, está sola circunstancia constituiría una razón suficiente para privar a una persona de su libertad, aunque en el caso concreto no haya motivo alguno que permita presumir que existe peligro de fuga o entorpecimiento. El proyecto original de Código Procesal Penal Federal, incluía la "conmoción social" como factor a tener en cuenta a la hora de dictar la prisión preventiva, finalmente se eliminó tras el rechazo de organizaciones y legisladores de la oposición y parte del oficialismo. Como se puede advertir a simple vista los dos motivos enunciados se encuentran íntimamente ligados al problema de la seguridad y al rol que están cumpliendo actualmente los medios de comunicación masiva.

En los últimos tiempos y acorde a la situación de crisis económica que viene sufriendo nuestro país, se puede observar un cambio en el eje de la información relativa a hechos criminales que éstos suministran a diario, colocándose en el centro de discusión a los delitos comunes, que naturalmente conllevan una mayor carga de violencia que los que se cometen detrás de un escritorio. La saturación de información en este sentido tuvo como resultado un aumento de la sensación de inseguridad de la población. Como siempre sucede cuando la sociedad entra en pánico, la solución que se propone es mayor represión.

Más allá de las consabidas apelaciones al aumento de penas, el encarcelamiento preventivo presenta las mejores características para satisfacer esta demanda; como se trata de una medida rápida, que no requiere de todos los pasos procedimentales previos que resultan necesarios para imponer una pena -ni tampoco el mismo grado de certeza- se la reclama porque se supone que, de ese modo, se está respondiendo adecuada y eficazmente en la lucha contra el delito porque los "delincuentes" obtienen inmediatamente la "sanción" que se merecen.

El mayor problema no radica, sin embargo, en el reclamo que puedan formular quienes no tienen por qué tener conocimientos técnicos para distinguir entre la pena y el encarcelamiento preventivo, sino en que aquellos que tienen la responsabilidad de gobernar se persuadan de la conveniencia de desnaturalizarlo para saciar las necesidades de apaciguamiento de la sociedad. 
Con lo que va dicho hasta aquí, lo que se pretende es afirmar la necesidad de separar los planos de la discusión. Los problemas de inseguridad deberán ser solucionados con medidas auténticamente preventivas, con el mejoramiento de las condiciones sociales o, en definitiva, con la implementación de las políticas que los responsables del tema estimen más adecuadas.

Pero en el paquete de medidas que se adopte, nunca podrá figurar el encarcelamiento preventivo. Éste debe quedar reservado para cumplir los únicos fines que, al menos en forma precaria, lo han justificado: los estrictamente procesales.

\section{V.- Bibliografía}

Beccaria, Césare (1955). De los delitos y las penas. Cap. XIX. Madrid: Ed. Aguilar.

Cafferata Nores, José (1988). La excarcelación. Buenos Aires: Ed. Depalma.

Carnelutti, Francesco (1965). Las miserias del proceso penal. Traducción de Santiago Sentis Melendo. Buenos Aires: Ed. El foro.

Carrió, Genaro (1994). Notas sobre Derecho y Lenguaje. Buenos Aires: Abeledo-Perrot.

Clariá Olmedo, Jorge (1966). Tratado de Derecho Procesal Penal. T. V. Buenos Aires: Ed.

Ediar.

Ferrajoli, Luigi (1997). Derecho y Razón. Teoría del garantismo penal. Madrid: Ed. Trota.

Foucault, Michel (2002). Vigilar y castigar. Nacimiento de la prisión. Buenos Aires: Siglo XXI.

González, Joaquín V. (1983). Manual de la Constitución Argentina. Buenos Aires: Angel Estrada y Cía.

Maier, Julio (1996). Derecho Procesal Penal. T. I. Buenos Aires: Editores del Puerto, 2da Edición.

Pastor, Daniel (1993). "El encarcelamiento preventivo”. En: El nuevo Código Procesal Penal de la Nación. Análisis crítico, AAVV, Editores del Puerto.

Pastor, Daniel (1997). "Recurso de Casación y anulación de oficio". En NDP, 1997-B, pp. $681 / 683$.

Pérez Barberá, Gabriel (1992). “Prisión Preventiva y Excarcelación”, en La Ley, Córdoba, pp. 1070/1077.

Pérez Duhalde, Ramiro (2015). "Principio de legalidad estricta en materia penal. Breve Historia y desvíos. El caso del terrorismo". En Revista Anales de la Facultad de Ciencias Jurídicas y Sociales de la Universidad Nacional de La Plata. Año $12 \mathrm{~N}^{\circ} 45$.

Disponible en http://sedici.unlp.edu.ar/handle/10915/50655

Pessoa, Nelson (1992). Fundamentos constitucionales de la exención de prisión y de la excarcelación. Buenos Aires: Hammurabi.

Rusconi, Maximiliano, (1997). "Prisión Preventiva y Límites del Poder Penal del Estado en el Sistema de Enjuiciamiento". En Revista La Ley, suplemento del 8/10/97, p. 3.

Solimine, Marcelo A. (2003). Tratado sobre las causales de excarcelación y prisión preventiva en el Código Procesal Penal de la Nación. Buenos Aires: Ad-Hoc.

Vélez Mariconde, Alfredo (1982). Derecho Procesal Penal. T. II. Córdoba: Marcos Lerner Editora, 3era edición. 